\title{
Shaping Form Sussex (the movie)
}

\author{
Ernest Edmonds \\ Institute of Creative Technologies \\ De Montfort University, Leicester \\ ernest@ernestedmonds.com
}

\section{SHAPING FORM SUSSEX (THE MOVIE)}

Shaping Form Sussex (the movie), 2012, is a digital film taken of Shaping Form Sussex, one of the time-based series consists of unique abstract interactive artwork that are each generating colours and forms in time from a set of unique rules: rules that are rather like their DNA. They also take data from a camera and continuously calculate the amount of activity seen in front of the work. The computer software then steadily modifies the rules. The artwork and its development over time is, then, influenced by the people who look at it. The audience help to shape the work. Shaping Form is a representation of computed life, moving and changing of its own accord but maturing and developing as a result of the movement of audiences. The shaping of the form is a neverending process of computed development. Shaping Form Sussex (the movie), can be viewed simply as a generative abstract film dealing with colour and simple shapes in a form of visual music.

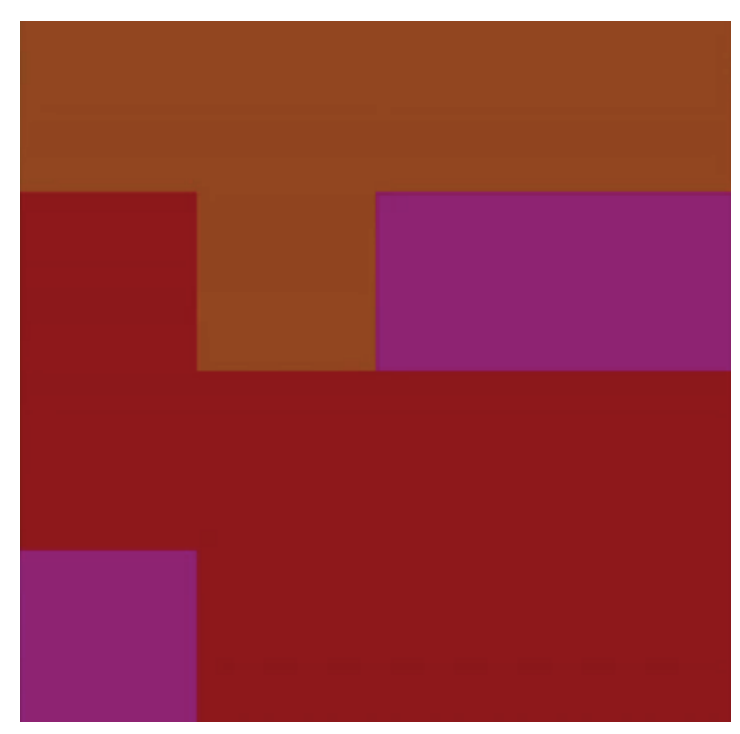

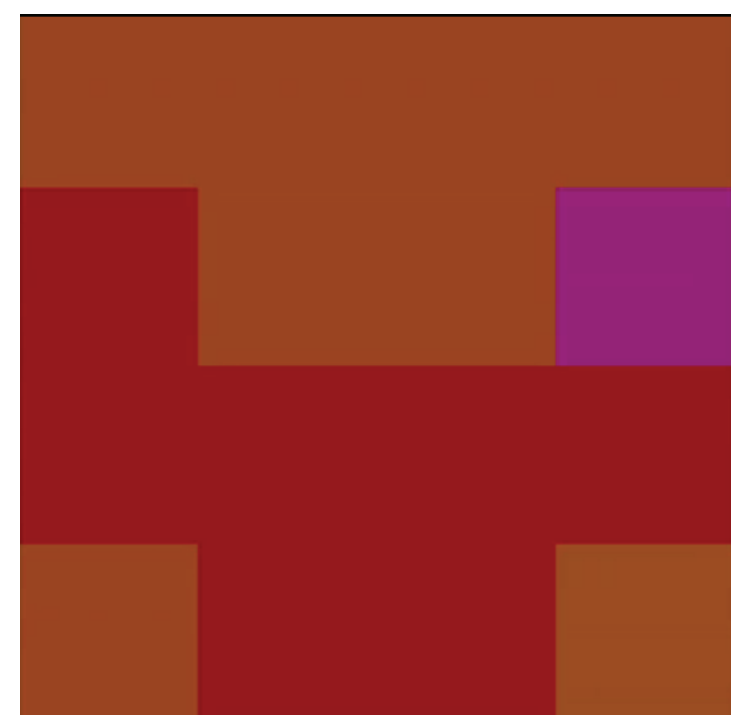

\section{BIOGRAPHICAL STATEMENT}

Ernest Edmonds was born in London in 1942 and, although he had already taken up painting as his main occupation, studied Mathematics and Philosophy at Leicester University. He has a PhD in logic from Nottingham University, is a Fellow of the British Computer Society, a Fellow of the Institution of Engineering and Technology and a Charted Engineer. He divides his time between the University of Leicester and the University of Technology Sydney, Australia. His art is in the constructivist tradition and he concentrates on systems, structures and computation. His work explores the implications of computational concepts for art practice in a number of dimensions. He first used computers in his art practice in 1968 and first showed an interactive work, with Stroud Cornock, in 1970. He first showed a generative time-based computer work in London in 1985. He has exhibited throughout the world, from Moscow to LA. The Victoria and Albert Museum, London, is collecting his archives within the National Archive of Computer Based Art and Design. 